\title{
Längeres und besseres Leben durch Palliativversorgung
}

Temel JS et al. Early palliative care for patients with metastatic non-small-cell lung

cancer. N Engl J Med. 2010;363:733-742

\section{Hintergrund und Fragestellung}

Patienten mit metastasiertem nicht kleinzelligem Bronchialkarzinom (NSCLC) leiden sehr unter den Symptomen und werden am Lebensende oft aggressiv behandelt. Die Wirkung einer früh nach der Diagnosestellung begonnenen Palliativversorgung bei ambulanten Patienten mit neu diagnostizierter Erkrankung wurde nun untersucht.

\section{Methodik}

Patienten mit neu diagnostiziertem, innerhalb von acht Monaten nach der Diagnosestellung metastasiertem NSCLC erhielten randomisiert entweder eine frühe Palliativversorgung zusammen mit der onkologischen Standardtherapie oder nur die onkologische Standardtherapie. Die Palliativversorgung beinhaltete die Visite durch ein Mitglied eines Teams aus Fachärzten für Palliativmedizin und spezialisiertem Pflegepersonal spätestens drei Wochen nach Studieneinschluss, danach mindestens monatlich, auf Wunsch des Patienten oder des Teams auch öfter. Der Schwerpunkt der nach den Leitlinien durchgeführten Palliativversorgung war die Beurteilung und Behandlung körperlicher und psychosozialer Symptome.

Die Lebensqualität und die Stimmung wurden zu Beginn und nach zwölf Wochen mithilfe der Functional Assessment of Cancer Therapy - Lung Scale (FACTL; 0-136 Punkte) und der Hospital Anxiety and Depression Scale beurteilt. Der primäre Zielparameter war die Änderung der Lebensqualität nach zwölf Wochen.

\section{Ergebnisse}

27 von 151 randomisierten Patienten waren innerhalb der zwölf Wochen verstorben. Bei 107 (86\% der verbliebenen) Patienten wurden die Beurteilungen vollständig durchgeführt.
Patienten mit einer frühen Palliativversorgung wiesen eine bessere Lebensqualität auf als diejenigen, die lediglich die Standardtherapie erhielten (98,0 vs. 91,5 Punkte; $p=0,03)$. Außerdem hatten in der Gruppe mit Palliativversorgung weniger Patienten depressive Symptome als in der Standardtherapiegruppe (16 vs. $38 \% ; \mathrm{p}=0,01)$. Am Lebensende erhielten Anzeige

in der Palliativversorgungsgruppe weniger Patienten eine aggressive Therapie als in der Standardtherapiegruppe (33 vs. 54; $p=0,05)$. Dennoch war die Überlebenszeit in der Palliativversorgungsgruppe länger (11,6 vs. 8,9 Monate; $\mathrm{p}=0,02)$.

\section{Schlussfolgerung}

Eine frühzeitige Palliativversorgung führte bei Patienten mit metastasiertem NSCLC zu einer signifikanten Verbesserung sowohl der Lebensqualität als auch der Stimmung. Im Vergleich zu Patienten mit alleiniger Standardtherapie erhielten Patienten mit einer Palliativversorgung seltener eine aggressive Therapie am Lebensende, hatten aber eine längere Überlebenszeit.

\section{Kommentar}

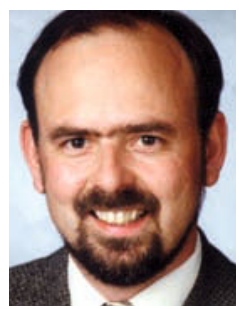

Prof. Dr. med. Klaus Mörike, Tübingen

Diese Ergebnisse zur frühen Integration einer Palliativversorgung bei Patienten mit metastasiertem NSCLC sind vielversprechend. Entgegen der weit verbreiteten Ansicht stellt die Palliativversorgung keine Alternative, sondern eine Ergänzung der krankheitszentrierten Therapie dar [1]. Die Gründe für die verlängerte Überlebenszeit sind bislang nicht bekannt.

Einige Limitationen dieser Studie sind bedenkenswert. Die Studie wurde an einem einzelnen spezialisierten Zentrum mit onkologischer und palliativmedizinischer Expertise durchgeführt. Die Ergebnisse können daher nicht für andere Versorgungssituationen und für andere maligne Erkrankungen verallgemeinert werden. Außerdem waren sich die Patienten und Versorger der Gruppenzuordnung bewusst. Hinzu kommt, dass Konsultationen durch das Palliativversorgungsteam den Patienten der Standardtherapiegruppe nicht verweigert wurden, wenn sie dies wünschten. Bei einer kleinen Zahl von Patienten war dies der Fall, und ihre Daten wurden - dem Intention-toTreat-Prinzip folgend - mit der Standardtherapiegruppe analysiert. Eine „Verdünnung" des wahren Therapieeffekts war daher möglich. Ferner konnte eine Unterschätzung des wahren Effekts durch das Vorgehen des Last Observation Carried Forward, d.h. bei Ausfall von Daten die Mitnahme des letzten erhaltenen Beobachtungspunkts an das Ende, entstehen.

Eine hohe Einschluss- und eine geringe Ausfallrate gehören zu den Vorteilen dieses Projekts im Vergleich zu bisherigen Studien, bei denen man auf eine Überweisung an das Palliativteam angewiesen war. Hinzu kommt eine adäquate Power für die Entdeckung von Änderungen der Lebensqualität und Stimmung.

\section{Literatur}

1. Kelley AS et al. Palliative care - a shifting paradigm. N Engl J Med. 2010;363:781-782 